\title{
DICIONÁRIOS DE JAMES CURTIUS HEPBURN E WASABURÔ ÔTAKE: UM POUCO MAIS SOBRE OS ADJETIVOS
}

Eliza Atsuko Tashiro ${ }^{l}$

Resumo: Damos continuidade aos estudos sobre os dicionários de Wasaburô Ôtake (18721994), um dos japoneses que estiveram no Brasil em anos anteriores ao início oficial da imigração japonesa. Chegou ao Rio de Janeiro em julho de 1890 e partiu de volta ao seu país em agosto de 1894. Neste artigo aprofundamos a análise de questões gramaticais presentes nos primeiros dicionários bilíngues que têm o japonês como língua de partida, dando ênfase ao tratamento dado pelos autores à classe de palavras que equivalem aos adjetivos. Como se sabe, os adjetivos e verbos do japonês, chamados respectivamente de keiyôshi/keiyôdôshi e dôshi na nomenclatura gramatical escolar, têm muitas características morfossintáticas em comum. O que chamou a atenção nos dicionários escolhidos nesta pesquisa - os dicionários de James Curtius Hepburn (1815-1911), publicados em 1867, 1872 e 1886, e o Wa po jiten (Ôtake 1925) -, foi a apresentação de diversas formas morfológicas dessas palavras, seja no lema, seja no interior dos verbetes. Ambos os autores mantêm a prevalecença dos keiyôshi e keiyôdôshi como palavras que desempenham a função de modificadores ou especificadores, mas fornecem também as formas assumidas por eles na função adverbial. Concluimos que, embora os dicionários forneçam os dados das formas gramaticais de maneira parcial - pois são apresentadas as formas adnominal (que é a mesma da forma final ou predicativa) e adverbial -, ao fazê-lo de forma sistemática auxiliam o consulente a entender uma das questões básicas da morfossintaxe japonesa.

Palavras-chave: W. Ôtake, J. C. Hepburn, dicionários, adjetivos, gramática

Abstract: Continuing the study on the dictionaries of Wasaburô Ôtake (1872-1994), one of the Japanese who were in Brazil 28 years prior to the official start of Japanese Immigration, in this article, we present the analysis of grammatical issues in the first bilingual dictionaries that have the Japanese as the source language. We emphasized the treatment given by the authors to the class of words that are equivalent to adjectives. As we all know, the adjectives and verbs of

1 Docente do Curso de Letras da Faculdade de Filosofia, Letras e Ciências Humanas da Universidade de São Paulo. 
Japanese, called respectively keiyôshi/keiyôdôshi and dôshi in the school grammar, have many morphological and syntactic features in common. In the dictionaries of this research - those of James Curtius Hepburn (1815-1911), published in 1867, 1872 and 1886, and the Wa po jiten (Ôtake 1925) - there are various morphological forms of these words, either as entry words, or within the articles. Both authors maintain the prevalence of the adnominal functions of keiyôshi and keiyôdôshi, but also provide the forms in the adverbial function. We conclude that although the dictionaries provide the data of the grammatical forms of partial way - because they presented the adnominal forms (which is the same as the final or predicative form) and adverbial ones -, they do consistently. It helps the user comprehend one of the more basic questions of Japanese morphology.

Keywords: W. Ôtake, J. C. Hepburn, dictionaries, adjectives, grammar

\section{Introdução}

Apresentamos uma análise das questões gramaticais presentes nos dicionários bilíngues japonês-inglês de James Curtius Hepburn (1815-1911) e de japonês-português de Wasaburô Ôtake (1872-1994), retomando uma pesquisa iniciada em 2008 por ocasião do centenário da imigração japonesa no Brasil, cujos resultados foram publicados parcialmente em Tashiro 2008a, 2008b², 2010 e 2015. Neste artigo, daremos ênfase nas classes dos keiyôshi e keiyôdôshi da língua japonesa - geralmente denominados adjetivos em português ou adjectives em inglês -, detalhando a análise de como essas palavras são descritas nas obras lexicográficas dos autores em questão.

James Curtius Hupburn é uma figura conhecida dos japoneses e dos ocidentais que estudam e pesquisam o Japão. Ele dá nome a um dos três sistemas de transliteração das palavras japonesas ao alfabeto, o qual é utilizado, por exemplo, pelo Ministério de Negócios Estrangeiros do Japão para grafar nomes dos japoneses em passaportes, embora o oficial seja o sistema Kunrei desde 1954. Médico missionário da Igreja Presbiteriana Americana, atuou também como educador e tradutor, tendo permanecido no Japão de 1859 a $1892^{3}$. Segundo cronologia de fundação ${ }^{4}$ da Meiji Gakuin University, uma escola particular de poucos alunos onde Hepburn ensinava medicina e sua mulher, Clara Mary Leete, língua inglesa, e aberta em 1863, daria origem à Meiji Gakuin em 1887, com a junção de várias mission schools, após autorização dada pela prefeitura de Tóquio para se instalar em Shirokane, onde se encontra até hoje o principal campus dessa universidade. Hepburn foi o seu primeiro reitor, de 1889 a 1891. Como tradutor participou ativamente de grupos e comissões de tradução do velho e novo testamento da biblia ao japonês,

2 A versão inglesa do mesmo texto é Tashiro 2009.

3 O Historical Museum da Meiji Gakuin University mantém uma exposição digital com uma breve biografia das personalidades fundadoras da instituição. Disponível em (consultado em 05/12/2016): http://shiryokan.meijigakuin.jp/archive/people/hepburn.

4 Disponível em http://www.meijigakuin.jp/history, consultado em 30/11/2016. 
cujas primeiras versões foram concluídas em 1887 e 1880, respectivamente. A sua atuação como médico é lembrada até hoje. Muito recentemente, em 2002, a associação do Curso de Medicina da Universidade da Cidade de Yokohama deu seu nome a um auditório multifuncional - chamando-o Hepburn Hall - em homenagem à dedicação de Hepburn à atividade médica, dando assistência gratuita a mais de 10 mil enfermos de Yokohama, sem distinção de classe social, durante quase 18 anos $^{5}$. Outra faceta muito conhecida Hepburn é como lexicógrafo, tendo publicado o primeiro dicionário bilígue japonês-inglês, a edição de 1867 de Wa ei gorin shûsei ou A Japanese and English dictionary with an English and Japanese index. Este dicionário foi reeditado em 1872 e, em 1886, saiu a terceira edição. Em todas existe a parte na direção inglês-japonês seja sob a denominação de index, como é o caso da edição de 1867, seja como um segundo dicionário, como no caso da reedição e no de 1886, muito embora a quantidade seja sempre inferior à parte japonês-inglês. A biblioteca da Meiji Gakuin University, em 2006, passou a tornar público no meio digital várias obras raras do seu acervo, iniciando com os dicionários de Hepburn, acrescentando várias informações relacionadas ao título bibliográfico principal, com base em pesquisas já realizadas por especialistas. Essa página, premiada em 2007 pela associação das bibliotecas de universidades privadas do Japão, está no endereço http://www.meijigakuin.ac.jp/mgda/ e contribuirá com os estudos e reestudos, em áreas de conhecimento diversas, de uma época em que o Japão era o centro do olhar de quase todo o mundo.

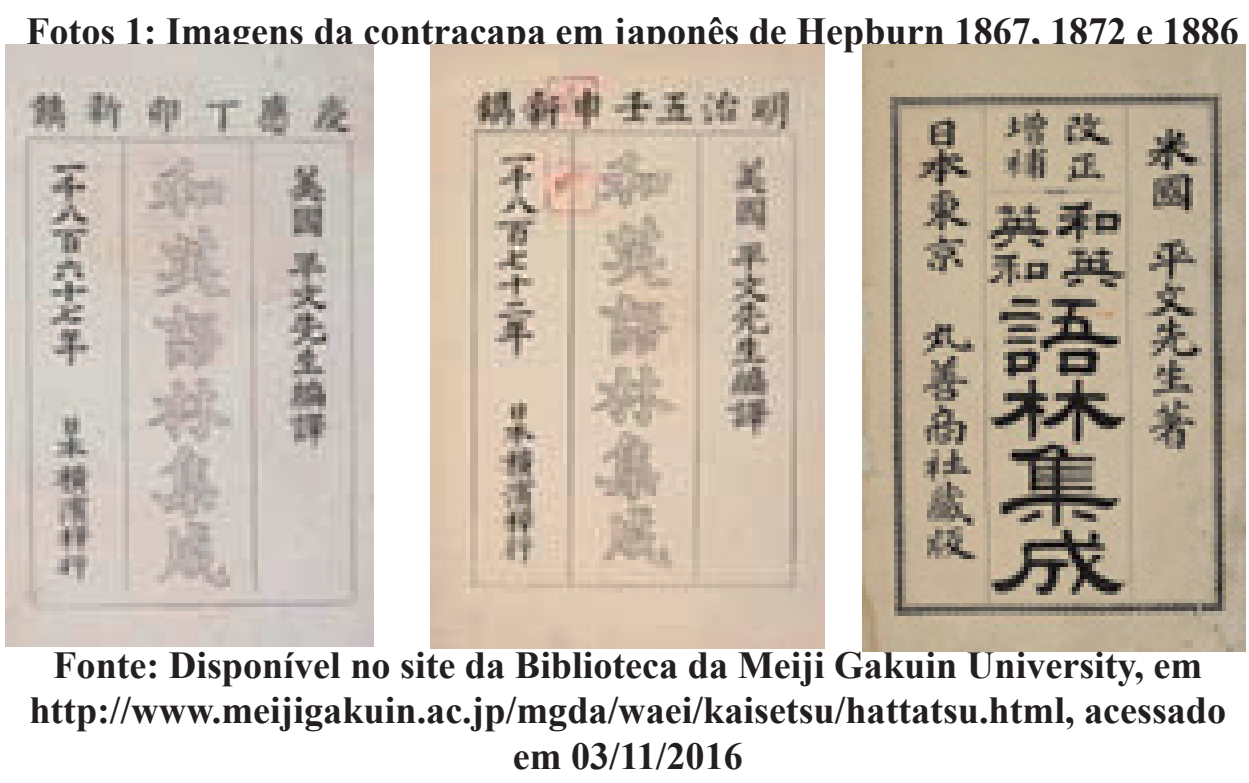

5 Informações disponíveis em http://www.gushinkai.org/archive/hepburn.html, acessado em 01/12/2016. 
Sobre Wasaburô Ôtake, Horie 2008 é quem traz a biografia mais completa e a resumimos em 2008b, 2010 e 2015. Lembramos que Ôtake foi um dos japoneses intimamente ligados com a atividade migratória ao Brasil e suas obras foram importantes para o cotidiano dos nipônicos nas terras brasileiras. Também cabe ressaltar que o autor não era especialista em estudos linguísticos, mas um grande entusiasta das relações entre as duas nações, traduzidas nos seus trabalhos em prol da imigração dos japoneses no país, e grande simpatizante do Brasil.

\section{Fotos 2: Contracapa dos dicionários de Wasaburô Ôtake (1918. 1925. 1937)}
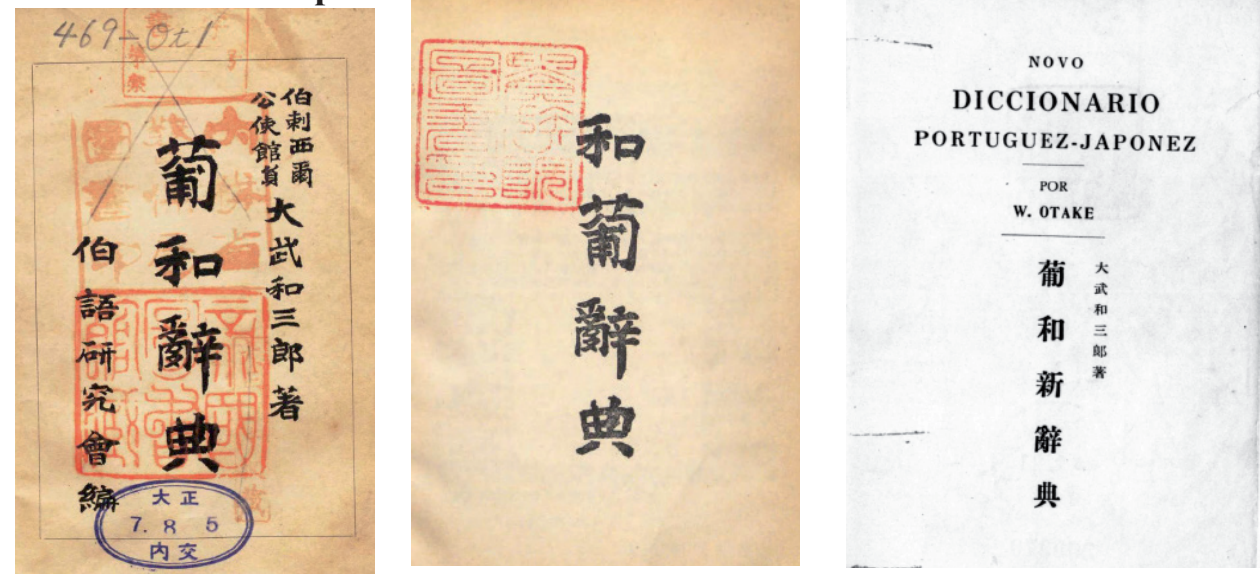

Fonte: http://dl.ndl.go.jp/ (acessado em 10/11/2016)

Ôtake nos legou três dicionários bilíngues, sendo que em todos eles o português é o do Brasil. As primeiras impressões de cada uma das primeiras edições foram custeadas pelo próprio autor. Po-wa jiten ou Diccionario português-japonês (1918) é a primeira obra lexicográfica publicada no sentido português-japonês, na história dos dicionários. O Wa-po jiten ou Diccionario japonês-português (1925) é o segundo do mundo no sentido japonês-português, editado mais de 300 anos após a publicação em Nagasaki/ Japão do Vocabulario da Lingoa de Japam, em 1603. O Po-wa shin jiten ou Novo diccionario português-japonês é uma reedição daquele de 1918, mas revisada e bastante ampliada. Para a nossa análise foi utilizado somente o Diccionario japonês-português.

Nos textos anteriores, descrevemos as características gerais dos verbetes e das classes dos verbos e adjetivos japoneses no Wa-Po Jiten ou Diccionario JaponezPortuguez, de Wasaburô Ôtake, primeiramente publicado em 1925, devido ao fato de serem os verbos e adjetivos as palavras que possuem variação desinencial diferente da do português e outras línguas neolatinas e também das do ramo germânico, com as quais se tem familiaridade no Brasil. E os comparamos com os verbetes dos dicionários de 
James Curtius Hepburn (1867, 1872 e 1886) e com o dos Jesuítas (1603). Concluímos em Tashiro 2008a, 2008b e 2010 que essas informações gramaticais trazidas no Vocabulario da Lingoa de Iapam, publicação da missão jesuítica no Japão, impresso em Nagasaki em 1603, foram mantidas em A Japanese and Englich Dictionary: with an English and Japanese index (HEPBURN, 1867) e também nas edições posteriores - de 1872 e 1886 -, mas desapareceram no Wa-Po Jiten de Ôtake. Tratam-se de mudanças que consideraram o tipo de consulente a quem se destinava cada dicionário e tem também a ver com a tendência das produções lexicográficas bilíngues em geral, ao longo do tempo.

Neste artigo, aprofundaremos a análise das descrições gramaticais nas obras lexicográficas bilíngues de Hepburn (1867, 1872 e 1886) e de Ôtake (1925), respectivamente os primeiros autores que incluíram o inglês e o português brasileiro, os quais passaram a ser línguas oficiais de parte importante do Novo Mundo. O foco foi dado na classe dos keiyôshi e keiyôdôshi, denominações da terminologia da gramática japonesa. Propõe-se, com mais esta análise, reunir elementos para entender as ideias linguísticas, mais especificamente sobre gramática, que Ôtake tinha e, consequentemente, contribuir para compreender as estratégias de descrição adotadas pelo autor para fazer entender o seu idioma numa situação lusófona.

\section{Um pouco mais sobre os dicionários bilíngues dos fins do século XIX e início do XX}

O Japão tem uma longa tradição em elaboração e produção lexicográfica.

Os nomes dos dicionários os quais citamos para esta breve cronologia foram apenas transliterados, no sistema Hepburn, mas não procedemos à tradução dos mesmos.

Os primeiros dicionários seguiram o modelo chinês e possuem características de um kanwa jiten (em tradução literal, dicionário kanji-japonês) ou seja, um dicionário que explica, em japonês, o significado e a origem dos ideogramas. O mais antigo que se conservou até os dias atuais chama-se Shinsen jikyô, elaborado por um monge de nome Shôjû (s.d.) e que foi finalizado entre os anos de 898 e 901.

O dicionário semasiológico considerado mais antigo é Iroha jiruishô, elaborado por volta de 1180, e de autoria atribuida a Tadakane Tachibana (s.d.), que indicou a forma de grafar a palavra em ideogramas, assim como o uso.

A unificação do Japão pelos Tokugawa e pacificação do país, possibilitou acesso à leitura e escrita da camada mais ampla da população, provocando, inclusive o aumento da procura por dicionários. Setsuyôsh $\hat{u}$ ou Setchûsh $\hat{u}$, cuja edição mais antiga conhecida é a dos anos de 1460, é de autoria desconhecida, mas foi sendo revisada e ampliada ao longo dos anos, tendo sido usado até os inícios do século XX, por ser de consulta fácil. Trata-se de um dicionário que contém palavras grafadas em ideogramas acompanhadas de sua leitura em fonogramas kana, por isso teria sido bastante funcional 
para o letramento. Embora sejam poucas as definições e explicações, como também os exemplos de uso, o Setsuyôshû agradou os recém letrados por conter a grafia em ideogramas de palavras, muitas das quais pertencentes ao léxico do seu cotidiano.

A reabertura do Japão ao contato com as nações do ocidente permite aos japoneses tomarem conhecimento de outras formas de elaboração de dicionários. Os próprios estrangeiros em solo japonês passam a produzir obras lexicográficas, principalmente dicionários bilíngues, dentre eles os do médico missionário James Curtius Hepburn (1815-1911).

Estimulados pela produção de grandes dicionários semasiológicos como o Webster's American Dictionary of the English Language (1 $1^{\text {a }}$ edição, 1828), filólogos japoneses passaram a produzir dicionários da língua japonesa. O primeiro trabalho nesse sentido é o Genkai, de Fumihiko Ôtsuki (1847-1928), publicado em 1891. Seguem-se outras obras, também de médio porte: Jirin (1907) de Shôsaburô Kanazawa (1872-1967), Jien (1935) de Izuru Shinmura (1876-1967), Jikai (1952) de Kyôsuke Kindaichi (1882-1971). Grandes dicionários ou enciclopedias de palavras também passaram a ser publicadas: Kazutoshi Ueda (1867-19237) e Kanji Matsui (1863-1945) foram organizadores de Dai Nihon Kokugo Jiten (1915-1919), em 4 volumes; Ôtsuki publicou Dai genkai (1932-1937), de 5 volumes. Após a segunda guerra, constituiu-se uma comissão específica para a elaboração de um grande dicionário (com 20 volumes e 45.000 palavras-entrada) que foi publicada, em 1972. Trata-se do Nihon Kokugo Dai jiten, cuja $2^{\mathrm{a}}$ edição, de $2000 / 2001$, foi revista e ampliada, passando para 50.000 palavras-entrada e 100.000 exemplos de uso.

Faremos, em seguida, um breve comentário sobre a indexação das entradas nos dicionários japoneses.

As tentativas de transliteração das palavras e sentenças da língua japonesa ao alfabeto latino podem ser analisadas cronologicamente por meio das três edições do dicionário Wa ei gorin shûsei (1867 e 1872) do Wa ei Ei wa gorin shûsei (1886), de James Curtius Hepburn. Quando, em 1918, Wasaburô Ôtake publicou o seu dicionário pioneiro Po wa jiten ou Diccionario Português-Japones, o uso do sistema Hepburn já estava bastante difundido. Mas é no Diccionario Japones-Portugues (1925) que a transliteração passa a ser usado, para grafar as palavras japonesas da entrada e das expressões ou frases exemplares. Nas Notas o próprio autor informa que a transliteração foi feita utilizando-se desse sistema.

E, como muitas obras lexicográficas do período, Hepburn e Ôtake utilizaram o critério alfabético para a indexação das entradas ou lemas.

$\mathrm{Na}$ história dos dicionários publicados no Japão, a indexação alfabética remonta ao fim do século XVI e início do XVII, quando os missionários jesuítas publicaram o Dictionarium Latino Lusitanicum ac, Iaponicum (1594) e o Vocabulario da Lingoa de Iapam (1603) nos quais as entradas de palavras latinas e japonesas - estas, após transcritas ao sistema alfabético criado segundo a fonologia e ortografia do português da época foram indexadas na ordem do abecedário. Mas são obras de europeus para europeus. 
Como nos referimos antes, o mais antigo dicionário de ideogramas contendo explicações em japonês, Shinsei jigyô (entre os anos de 898 e 901) lista os ideograma de acordo com a raiz dos mesmos.

A indexação em ordem fonológico-silábica iroha-jun pode ser vista pioneiramente em Iroha jiruishô (1180). Este dicionário de ideogramas, que reúne palavras de fins do período Heian (794-1185), organiza primeiramente as palavras com um ou mais ideogramas pela ordem iroha da sua primeira sílaba, formando 47 grupos pois é esse o número de caracteres silábicos que compõem a tabela iroha ${ }^{6}$. Em seguida em cada grupo, as palavras estão subcategorizadas em vinte e um campos semânticos ${ }^{7}$ (Yamada 1978: 116-117).

O dicionário que apresentou, pela primeira vez, a indexação em gojûon-jun ${ }^{8}$ é Onkochi shinsho (escrito por volta de 1484), de Hirokimi Ôtomo (s.d.). Mas em cada seção das palavras que se iniciam com a sílaba do gojûon, fez nova tipificação das palavras conforme campos semânticos.

O dicionário que foi popular entre o período Edo (1603-1868) e início dos anos de 1900, Setsuyôshû segue a tradição do Iroha jiruishô (1180), ou seja, a indexação iroha-jun e posterior subcategorização em campos semânticos.

Dentre os dicionários de consulta apenas por campo semântico, Kagakush $\hat{u}$ foi o mais popular até a primeira metade do período Edo (1608-1868), quando cedeu sua primazia para Setsuyôsh $\hat{u}$. Elaborado em 1444, sua autoria vem registrada como sendo de Hanô Tôroku (s.d). Até os primeiros anos do século XVII circulou em versão abreviada, vindo a ser publicada dicionário completo somente em 1617.

$\mathrm{Na}$ chamada era moderna, a indexação das palavras japonesas em ordem alfabética em dicionários publicados no Japão se iniciou com a produção de dicionários e vocabulários bilíngues japonês-inglês e inglês-japonês. E foi justamente por obra de James Curtis Hepburn, ao publicar, em 1867, o Wa Ei Gorinshûsei ou A Japanese and English dictionary; with English and Japanese index. Este dicionário, segundo Kindaichi (1996) e Kurashima (2002), é um verdadeiro dicionário que descreve o léxico da língua japonesa, com informações sobre seu significado e exemplos de uso - ou seja, um dicionário semasiológico, de pouca tradição no Japão -, mas que o faz em inglês.

Em 1915, Kazutoshi Ueda (1867-1937) publicou o primeiro dicionário de japonês, monolíngue, cuja indexação das entradas é pelo alfabeto latino - o Rômajibiki kokugo jiten (Dicionário de língua japonesa de consulta pelo alfabeto latino), cujo

6 Os caracteres silábicos da tabela iroha, transcritos, são: i ro ha ni ho he to chi ri nu ru wo wa ka yo ta re so tsu ne na ra um u wi no o ku y ama ke fu ko e te a sa ki yu me mi shi we h imo se su

7 Os 21 campos semânticos, traduzidos, são: astronomia/estações, geografia/habitação, vegetação, fauna, relações humanas/moral, partes do corpo, assuntos humanos, alimentação, miscelâneas, cores, direção, números, miscelâneas/palavras de 1 kanji, palavras de kanji duplicado, sinônimos, santuários, templos, unidade político-administrativa, cargos/funções administrativos, sobrenomes e nomes.

8 Gojûon é o quadro de sílabas de 5 linhas e 10 colunas cujas sílabas iniciais são, na ordem, a ka sa ta na ha ma ya ra wa. 
título foi mudado depois para Rômaji de hiku kokugo jiten [Idem]), numa época em que se discutia a modernização da ortografia japonesa. No mesmo ano, Takeo Sakaeda (s.d.) e Hisakichi Kondô (s.d.) também publicaram um dicionário do japonês de consulta pelo alfabeto latino, o Kokkan jiten - Rômaji sakuin (Dicionário de japonês com consulta pelo alfabeto latino).

\section{Retomando nossa análise dos dôshi ou verbos}

Recuperando um pouco as ideias desenvolvidas nos artigos anteriores, ilustraremos com os verbetes de "sabaqi", "sabaki" ou "sabaku" dos três dicionários analisados, respectivamente.

No Vocabulario da Lingoa de Iapam (1603) os verbos nas suas entradas apresentam a forma chamada continuativa (em japonês, ren'yôkei ou chûshikei), seguida das desinências da forma final (em japonês, shûshikei) e da desinência continuativa aglutinada com o morfema "ta" que indica o aspecto perfectivo ou tempo passado, após sofrer eufonia de "qi" para "i". Exemplificamos, no quadro 1, com o verbete de "sabaqi, qu, aita", cujas formas verbais devem ser entendidas, respectivamente conforme abaixo:

sabaqi $\rightarrow$ forma continuativa

(saba)qu $\rightarrow$ forma final

(sab)aita $\rightarrow$ forma continuativa acrescida do morfema perfectivo/passado $t a$, após eufonia de qi para $i$

James Curtis Hepburn, em A Japanese and English dictionary: with an English and Japanese index (1867), manteve a mesma apresentação do lema, ou seja:

SABAKI, $-k u,-i t a$, サバク , 別, t.v...

Mas, a transcrição foi alterada, com o uso da letra " $k$ " ao invés de " $q$ " e corrigida a segmentação da desinência da forma continuativa mais o morfema "ta", de "aita" para "-ita". Além disso, em Hepburn 1867 as desinências isoladas vêm precedidas do sinal "-", para indicar que se trata de desinência e que a mesma é posposta ao radical da palavra. Foi também acrescida a transcrição em letras do silabário katakana da primeira palavra do lema - サバク - e também o ideograma equivalente usado na época - 別 -, sem desinência. Há, ainda, a inserção da classificação morfológica - t.v., isto é, transitive verb -, prática que se tornou comum nos dicionários japoneses e sobre o japonês após Hepburn incluir esse tipo de informação gramatical nessa edição de 1867. Na reedição de 1872 não há alteração nessa apresentação. Há apenas mudança na forma de transliteração de algumas sílabas, como as sílabas sublinhadas de "Motszre" e "saiban szru" que passaram a ser grafadas "Motsure" e "saiban suru". Na terceira 
edição, de 1886, a terceira forma foi descartada, e a entrada se resume a duas formas "sabaki" e "(saba)ku". Outra mudança, embora não relacionada à questão gramatical, foi o acréscimo de um equivalente: to manage.

O Diccionario Japonez-Portuguez (ÔTAKE 1925), por sua vez, adota o formato atual dos verbetes que trazem, na entrada, os verbos somente na forma final/shîshikei, ou seja, "sabaku". Segue-se a mesma palavra escrita em grafia japonesa: geralmente o radical em ideogramas (caso de 別, no verbete citado) e a desinência (ou parte dela) com letra do silabário hiragana (no caso, $<$ ).

\section{Quadro 1: Comparativo do verbete sabaqi/sabaki/sabaku em Jesuítas 1603, Hepburn 1867, 1872 e 1886, e Ôtake 1925 Vocabulario da Lingoa de Japam (JESUITTAS (1603, p. 426)}

Sabaqi, qu, aita. Desempeçar fios, cabelos da cabeça, \&c. Vt Camiuo sabaqu. Desempeçar os cabelos da cabeça.

Sabaqi, qu, aita. Ter cuidado, \& negocear as cousas da casa, \&c. Vt, Iye, chiguiǒ, nandouo sabaqu. Ter cuidado, \& administrar a casa, renda, \&c.

\section{A Japanese and English dictionary (HEPBURN 1867, 1872 e 1886)}

Sabaki, -ku, -ita, サバク, 別, t.v. To disentangle, unravel, loose; to sell off; to judge, to examine and decide a matter. Motszre wo -, to disentangle. Kuji wo -, to try a lawsuit. $\mathrm{Ni}$ wo - , to sell off goods.

Syn. Hodoku, saiban szru. (1867, p. 363)

Sabaki, -ku, -ita, ザ 开ク, 別, t.v. To disentangle, unravel, loose; to sell off; to judge, to examine and decide a matter. Motsure wo -, to disentangle. Kuji wo -, to try a lawsuit. $\mathrm{Ni}$ wo -, to sell off goods.

Syn. Hodoku, saiban suru.

(1872, p. 420)

Sabaki, -ku サバク 別 t.v. To disentangle, unravel, loose; to sell off; to judge, to examine and decide a matter, to manage; motsure wo -, to disentangle; kuji wo -, to try a lawsuit; ni wo -, to sell off goods; suso sabaki ga dekinu, cannot manage her skirts properly.

Syn, hodoku, saiban suru.

(1886, p. 516)

\section{Diccionario Japonez-Portuguez (ÔTAKE 1925, p.418)}

Sabaku 別<, v.t. Vender (販賣)// Julgar; Examinar e decidir (審判)// Despachar (處理)// Desemmaranhar (解縺)// Destrinçar; desenredar (紛紏の解決).

O Vocabulario (1603), dos Jesuítas, e Hepburn (1867, 1872 e 1886) têm em comum apresentar a entrada dos verbos japoneses na forma hoje chamada ren'yô (ou chûshihô, continuativa). O padre João Rodrigues (1558-1633), membro da Companhia de Jesus em missão no Japão nos séculos XVI e XVII, em sua Arte da Lingoa de Japam 
(1608) chamou essa forma de "rayz" do verbo como quando afirmou "Ari, $\underline{\text { rayz do }}$


também explicou que se tratava da raiz do verbo, a qual termina em $i$ ou $e$, e que também tem o sentido de indefinido: "...The root form of every verb terminates in either $i$ or $e$, and is also indefinite in meaning." (1872, p. xx, grifo nosso)

Uma das conclusões em Tashiro 2010 fora de que fornecer as formas gramaticais era de grande utilidade para os consulentes que não sabem ou dominam muito pouco as regras de flexão dos verbos. Interpretando a terceira forma - destacada em negrito - em Jesuítas (1603) e Hepburn (1867 e 1872), temos:

Sabaqi, qu, aita $\rightarrow$ sabaqi $\rightarrow$ sabaita (Jesuítas 1603)

Sabaki, -ku, -ita $\rightarrow$ sabaki $\rightarrow$ sabaita (Hepburn 1867 e 1872)

Essa prática seria muito funcional até mesmo nos dias de hoje. A gramática normativa japonesa explica essa passagem de "sabaqi/sabaki" para "sabaita" como sendo mudança fonética da última sílaba ao se juntar com o morfema "ta", que ocorre com a maior parte dos verbos. Ou seja, no caso de "sabaqi/sabaki" ocorreria o seguinte processo:

Sabaqi/sabaki + ta $\rightarrow$ sabai + ta $\rightarrow$ sabaita

Trazer a palavra-entrada com essas informações significa economizar a explicação desse processo e, para os consulentes não usuários ou aprendizes do idioma o benefício de não errar ou, pelo menos o de correr menor risco de erro.

\section{Apresentação das formas gramaticais dos adjetivos japoneses}

Sobre os adjetivos, em Tashiro 2008a e 2010 discutimos a apresentação dos verbetes dos dois tipos - keiyôshi e keiyôdôshi-, exemplificando com "abunai" e "ada". Resumimos, a seguir, a ideia contida nesses trabalhos e, ao mesmo tempo, aprofundamos a nossa análise.

\subsection{Formas gramaticais dos keiyôshi}

No caso dos adjetivos chamados keiyôshi na gramática japonesa, Hepburn (1867, 1872 e 1882) é quem apresenta maior número de formas morfológicas, como podemos ver no quadro abaixo no qual reproduzimos os verbetes do adjetivo "abunai". 


\begin{tabular}{|c|c|c|}
\hline Hepburn 1867, p. 1 & Hepburn 1872, p. 2 & Hepburn 1886, p. 2 \\
\hline $\begin{array}{l}\text { ABUNAI, -KI, -shi, } \\
\text { ブナイ, 浮雲. a. } \\
\text { Dangerous. Abunai, } \\
\text { take care. Abunai } \\
\text { koto, a dangerous } \\
\text { thing. Syn. AYAUI, } \\
\text { KENNON. } \\
\text { ABUNAKU, or ABUNō, } \\
\text { アブナク、浮雲, } \\
\text { adv. idem. Abunaku } \\
\text { nai, no danger. }\end{array}$ & $\begin{array}{l}\text { ABUNAI, -KI, -SHI, 浮雲, a. } \\
\text { Dangerous, perilous, hazardous, } \\
\text { Abunai, take care. Abunai koto, } \\
\text { a dangerous thing. Abunaku nai, } \\
\text { there is no danger. Abuno gozari- } \\
\text { masu, it is dangerous. Abunakute } \\
\text { yukare-nai, it is dangerous and I } \\
\text { cannot go. / Syn. AYAUI, KENNON. }\end{array}$ & $\begin{array}{l}\text { ABUNAI アフ } \\
\text { of Abunaki. } \\
\text { ABUNAKI, -KU, -SHI アブナキ } \\
\text { 危 adj. (coll.) Dangerous; } \\
\text { perilous; hazardous; } \\
\text { insecure; abunai, take care! } \\
\text { look out! Abunakunai, there } \\
\text { is no danger; abunakute } \\
\text { yukarenai, it is dangerous } \\
\text { and I cannot go; abunai koto, } \\
\text { or abunai me, a dangerous } \\
\text { affair. } \\
\text { ABUNŌ アブナウ adv. (coll. } \\
\text { cont. of abunaku) vid. } \\
\text { abunaki; -gozarimasu, it } \\
\text { is dangerous; take care! } \\
\text { (polite). }\end{array}$ \\
\hline
\end{tabular}

Nas três edições de Hepburn, temos as seguintes formas, distribuídas em diferente número de verbetes. Entre parênteses colocamos o verbo ou parte dele cuja forma é possível supor, seja pela desinência dada, seja pelo exemplo de uso fornecido pelo autor.

Abunaku - forma continuativa/chûshihô ou adverbial/ren'yô como indicado com a abreviação adv., e exemplificado com “Abunaku nai, no danger” (1867 e 1872), "abunakunai, there is no danger" (1886) e "abunakute yukare-nai, it is dangerous and I cannot go" (1872) e "abunakute yukarenai, it is dangerous and I cannot go" (1886)

Abunō - forma continuativa/chûshihô ou adverbial/ren'yô, como forma alternativa ao "abunaku", e é a forma coloquial e contraída. Está exemplificada com "Abonō gozari-masu" (1872) e "(abonō) gozarimasu" (1886)

(abuna)-shi - forma final/shîshi

(abunai) - forma final/shûshi (língua coloquial) exemplificado com "abunai, take care" (1867 e 1872) e "abunai, take care! look out!” (1886)

abunai - forma atributiva/rentai (forma contraída de "abunaki") exemplificado com "abunai koto, a dangerous thing"

(abuna)-ki - forma atributiva/rentai

No Vocabulario da Lingoa de Iapam (JESUÍTAS 1603) o adjetivo na forma atributiva/rentai constitui a entrada e é complementada com a forma substantiva com o sufixo “-sa”, e a forma adverbial/ren ’yô, “abunŏ” que na grafia japonesa escreve-seあ ぶなう. Essas formas estão recuadas da margem esquerda. 
Abunai. Cousa perigosa, ou posta a perigo.

Abunasa.

Abunŏ.

(JESUÍTAS 1603, p.2)

Em Ôtake 1925, o verbete de "abunai" possui somente os possíveis equivalentes e o único exemplo é " - interj. Cuidado!”. A forma apresentada no lema pode ser a forma final/shûshi ou atributiva/rentai, pois a desinência é a mesma (-i). Entretanto, os adjetivos keiyôdôshi, entre parênteses, que acompanham os equivalentes em português, se encontram na forma atributiva, com a desinência な (na): 危険な 冒険な 危急な不 安な 重大な 至難な, o que nos leva a supor de Ôtake dava destaque à função atributiva dessa classe de palavras. Ou seja, a função atributiva seria a função principal dessas palavras chamadas keiyôshi.

Para informar a forma adverbial/adverbial, o autor introduziu outro verbete, "abunaku", cuja classe gramatical é definida como sendo um advérbio (ÔTAKE 1925, p. 1):

Abunai 危い 9 , $a$. Perigoso (危険な)// Arriscado (冒険な)// Critico (危急な)// Receioso ( 不安な)// Grave (重大な)// Precario (至難な)// Duvidoso (疑わしい)// -, interj. Cuidado!

Abunaku 危 $<, a d v$. Por um pouco; a quase; ao ponto de.

Citamos um outro verbete que mostra melhor as diferentes formas do mesmo adjetivo. Tratam-se de "atarashii" e "atarashiku" (ÔTAKE 1925, p. 16):

Atarashii新らしい ${ }^{10}, a$. Novo// Fresco (新鮮な)// Moderno (11斬新の, 近代 の)// Recente (近頃の)// Novo em folha, do trinque (手付かざる).

Atarashiku 新しく, $a d v$. Novamente; de novo// Recentemente (最近に)// suru, Renovar.

Percebe-se que, como aconteceu com "abunai", Ôtake separou as formas atributiva/rentai e adverbial/ren'yô em dois verbetes diferentes atribuindo a classificação morfológica de acordo com a função sintática. Foram mantidas as equivalências não só semântica como também a gramatical: "novo", "fresco", "moderno", "recente" são adjetivos; assim como são advérbios ou expressões adverbiais, "novamente", "de novo" e "recentemente".

No verbete de "atarashii", temos uma novidade de natureza gramatical. As palavras que acompanham os equivalentes do português "moderno" e "recente", ou seja 斬新の, 近代の e 近頃の estão na forma atributiva. Podemos interpretar como sendo:

9 A ortografia dos ideogramas foi atualizada.

$10 \mathrm{Na}$ ortografia moderna, -se 新しい. Somente após a segunda guerra mundial ocorre a sistematização das normas ortográficas que passam a ser, inclusive, ensinadas nas escolas.

11 Idem. 
i) substantivos flexionados no caso genitivo, com a desinência $の$; ou ii) morfema gramatical (ou partícula) $の$ posposto aos substantivos 斬新, 近代 e 近頃.

Embora Ôtake não apresente nenhuma explicação sobre a formação morfossintática dos adjuntos adnominais, uma observação atenta dos verbetes permite perceber que:

- as palavras denominadas keiyôshi na gramática japonesa estão classificadadas como adjetivos em Ôtake $1925^{12}$ e constituem lemas, vindo acompanhadas com a abreviação $a$., de adjetivo;

- essas palavras-entrada estão na forma chamada rentaikei ou atributiva;

- Ôtake mantém a equivalência gramatical, fornecendo-nos equivalentes, em português, também da classe dos adjetivos;

- os itens lexicais japoneses, entre parênteses, que acompanham os equivalentes em português, são sinônimos da palavra-entrada e estão também no uso atributivo:

a) as palavras chamadas keiyôdôshi formando sintagma de atributo com a finalização com な, como em 新鮮な;

b) a palavras da classe dos meishi, daimeishi e sûshi-equivalentes aos substantivos, pronomes e numerais, respectivamente - formando sintagmas com finalização em $の$, como em 斬新の, 近代の e 近頃の;

c) as palavras da classe dos dôshi (equivalentes aos verbos) ou os sintagmas verbais, também na forma rentaikei ou atributiva, como é o caso de 手付かざる.

- a forma adverbial/ren'yôkei, que é também a forma continuativa/chûshihô, é informada em verbete distinto, como lema, e leva a classificação de advérbio, pois vem seguida da abreviação $a d v$.

A inserção do trecho "-suru, Renovar" indica o uso adverbial, ou seja "atarashiku" é a forma que precede um verbo, no caso "suru (fazer)". O conjunto "atarashiku suru" (literalmente, fazer novo), devido ao fato de poder ser interpretado renovar, foi entendido como um novo verbo.

\subsection{Formas gramaticais dos keiyôdôshi}

A língua japonesa tem um outro grupo de palavras que são chamados de keiyôdôshi na gramática normativa e que também possuem a propriedade de modificar um nome, à semelhança dos adjetivos. Citamos "ada" ou 'ada-na" de Jesuítas (1603), Hepburn (1867, 1872 e 1886) e Ôtake (1925) para explicar como cada dicionário descreveu essa classe de palavras.

O Vocabulario da Lingoa de Iapam (1603), dos Jesuítas, informa na entrada apenas o radical, tratando-o como substantivo, mas traz um dado importante: "Não se usa persi senão Adana, I, Adano", ou seja, "ada" seria uma forma que possui significado

12 Em outros dicionários e vocabulários bilíngues anteriores a Ôtake 1925 também são denominados adjetivos e entendem que a função principal é a atributiva, assim como Hepburn. 
semântico, mas que necessita da parte desinencial para operar numa frase. Esse dado é reiterado em outro verbete, cujo lema é a palavra "ada" seguida das desinências da forma atributiva/rentai, "na" e "no".

Ada. Não se usa persi senão Adana, I, Adano. Coube breue, vaã sem proveito, \&c. ๆ Vt, Adano nasaqe. Amor vão, breue, \&c.

Adana, I, Adano. Couve breue vaã, \& de pouca dura.

(JESUÍTAS 1603, f. $3 \mathrm{v}$ )

Sobre como Hepburn nos apresenta essa classe de palavras, reproduzimos no quadro 2 os verbetes de "ada-na", “ada-ni" e "ada" nas três edições do seu dicionário.

\section{Quadro 2: As formas flexionais de "ada" e "ada-na" em Hepburn 1867, 1872 e 1886}

\begin{tabular}{|c|c|c|}
\hline Hepburn 1867, p. 2 & Hepburn 1872, p. 3 & Hepburn 1886,p. 2 \\
\hline $\begin{array}{l}\text { ADA-NA, ア \&, 虚. } \text {. False, } \\
\text { empty, vain, deceitfull; } \\
\text { fleeting, transitory. -kokoro, } \\
\text { false-hearted. Tszyu yori mo } \\
\text { adanaru inochi, a life more } \\
\text { fleeting than the dew. }\end{array}$ & 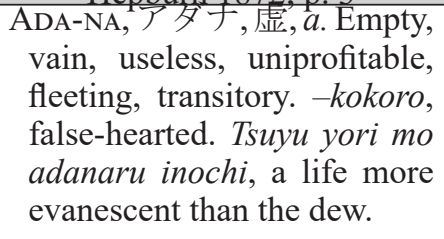 & $\begin{array}{l}\text { ADA } 8 \text { (used only } \\
\text { in comp.) Vain; empty; } \\
\text { useless; fruitless; } \\
\text { inaffectual; trifling; fickle; } \\
\text { frivolous; transitory; frail; } \\
\text {-na, or -naru, adj. id. - }\end{array}$ \\
\hline $\begin{array}{l}\text { ADA-NI, アダ二, 虚, } a d v \text {. } \\
\text { Falsely, vainly. }\end{array}$ &  & $\begin{array}{l}n l, a d v \text {. vainly, uselessiy; } \\
\text { improfitably: issen no } \\
\text { ada-zeni wo tsukawazu, } \\
\text { not spending one penny } \\
\text { uselessly. }\end{array}$ \\
\hline
\end{tabular}

Pode-se observar que nas edições de 1867 e 1872, Hepburn a classificou como adjetivo - com a abreviação $a$. - , fornecendo a forma atributiva/rentai pois vem com o acréscimo da desinência "-na". Em ambas as edições a forma adverbial/ren'yô "adani" é separada, em verbete distinto, e acompanhada da abreviação $a d v$. O uso antes de "kokoro" (sentimento) faz supor a expressão "adana kokoro" (falso sentimento), na qual a desinência "-na" e a posposição ao substantivo mostram que se trata de uma forma atributiva/rentai. Os exemplos frasais "Tszuyu yori mo adanaru inochi, a life more fleeting than the dew" (1867) ou "Tsuyu yori mo adanaru inochi, a life more evanescente than the dew" (1872) contém o uso da palavra, mas com a desinência arcaica "naru", sobre a qual só existe referência na edição de 1886, em que ambas desinências, "-na" e "- naru", seguidas da abreviação adj. faz o consulente supor que se tratam da forma atributiva/rentai.

No entanto, notamos que mesmo nas edições de 1868 e de 1872, a maior parte dos keiyôdôshi foi registrado como na edição de 1886, ou seja, a palavra-entrada sem desinência. Alguns estão registrados sem a abreviação da classe dos adjetivos, o que 
indica que o lema é um substantivo ou semelhante a ele; mas, muitos são classicados como nomes, com a abreviação $n$. Na edição nova, as informações das variações desinenciais se encontram no interior do verbete, as quais entendemos da seguinte maneira:

(ada)na ou (ada)naru - indicados com a abreviação adj., são a forma atributiva/ rentai, sendo que -naru é a desinência da forma arcaica.

(ada)ni - indicado com a abreviação $a d v$., é a forma adverbial/ren'yô.

Citamos em novo quadro o verbete de "shin-setsz", "shin-setsu" e "shinsetsu", respectivamente das edições de 1867, 1872 e 1886, para que seja melhor percebido o que explicamos acima.

\section{Quadro 3: As formas flexionais nos verbetes de "shin-setsz", "shin-setsu" e "shinsetsu" em Hepburn 1867, 1872 e 1886}

\begin{tabular}{|c|c|c|}
\hline & Hepburn 1872,p. 471 & Hepburn 1886, p. 575 \\
\hline $\begin{array}{l}\text { SHIN-SETSZ, } \\
\text { n. Kindness, benevolence. - } \\
\text { na hito, a kind person. - ni, } \\
\text { kindly. Syn. NEGORO. }\end{array}$ & $\begin{array}{l}\text { SHIN-SETSU, } \\
\text { ンセツ, 深切, } n . \\
\text { Kindness, friendliness, } \\
\text { benevolence. }- \text { na hito, } \\
\text { a kind person. - ni, } \\
\text { kindly. Svn. NENGORO. }\end{array}$ & $\begin{array}{l}\text { SHINSETSU } \\
n \text {. Kindness, friendliness, } \\
\text { benevolence: - na hito, a kind } \\
\text { person; - ni, kindly; go - wa } \\
\text { arigatō, thank you for your } \\
\text { kindness. Syn. NENGORO. }\end{array}$ \\
\hline
\end{tabular}

A classe de palavras a que Hepburn vinculou esse keiyôdôshi foi na classe dos nomes, indicada pela abreviação $n$., de noun, sobre o qual Hepburn observa que não possuem variação morfológica (Hepburn diz "mudanças em suas sílabas") para indicar caso, gênero ou número ${ }^{13}$. Assim sendo, todos os equivalentes em inglês são também nomes substantivos: "kindness", "benevolence" e "friendliness". O consulente supõe que o acréscimo da desinência "-na" seja a forma atributiva/rentai devido à colocação preposta a "hito" (pessoa), que deve formar a expressão "shinsetszna/ shinsetsuna hito"; e que, igualmente, a posposição da desinência "-ni" constitua a forma adverbial/ren'yô shinsetszni/ shinsetsuni cujo equivalente é o advérbio "kindly" (gentilmente). A manutenção, por Hepburn, da equivalência semântica, e principalmente, da gramatical permite essa compreensão.

Publicado quase 40 anos após a terceira edição de Hepburn, o Diccionario Japonez-Portuguez de Wasaburô Ôtake classifica as palavras da classe keiyôdôshi como substantivo.

Ada 徒, $s$. Aquillo que é vão ou inútil// -na, Vão; inútil// -ni, Em vão// -na nozomi な望, Esperança vã ou irrealisavel.

(ÔTAKE 1925, p. 2)

13 The Noun is not subject to any changes in its syllables to designate either case, gender, or number. (HEPBURN 1872, p. xvi; 1886, p. xiv) 
Informa o uso atributivo/rentai e adverbial/ren 'yô procedendo a uma equivalência gramatical:

- (ada)na - à essa forma atributiva/rentai, Ôtake fornece o equivalente "vão" e "inútil", ambos da classe dos adjetivos;

- (ada)ni - à essa forma adverbial/ren'yô, é dada a expressão adverbial equivalente "em vão";

- (ada)na nozomi (徒)な望み, Esperança vã ou irrealisavel - este exemplo de uso da forma atributiva/rentai vem acompanhada da tradução em equivalência semântica e gramatical.

Como dissemos no início do texto, Ôtake não era linguista, apesar da grande facilidade em aprender língua estrangeiras - fora intérprete japonês-inglês do príncipe Augusto Leopoldo (1867-1922), neto de D. Pedro II, durante sua estadia no Japão; aprendeu português e se tornou tradutor e intérprete da legação brasileira em Tóquio. A sistematização da morfossintaxe japonesa, feita por estudiosos da língua no meio acadêmico, esta ainda em fase de discussões e rediscussões, além de não estar consolidado nas escolas. Sendo assim, se justifica as inconsistências gramaticais no dicionário de Ôtake, como por exemplo, os verbetes como os que seguem. São verbetes de palavras que pertencem à mesma classe dos keiyôdôshi, como “ada 徒”, mas nestes o lema é classificado como adjetivo e a forma dada é atributiva/rentai, com a desinência "na".

Ada-na 邚可娜な, $a$. Lindo; chique; elegante.

(ÔTAKE 1925, p. 2)

Kwappatsu-na 活發な, $a$. Vivo; active; desembaraçado. (Idem, p. 292)

O segundo verbete tem a ver com as tentativas que ainda se faziam de escolha das letras fonográficas kana, por exemplo entre "ka" ou "kwa", sua respectiva transliteração, pois existe na mesma obra o verbete seguinte, o qual mantém a mesma apresentação de “ada 徒”.

Kappatsu 活發, s. Actividade; vivacidade// Desembaraço (自由活動)// Animação (活氣)// - na, Animado// - ni, Com actividade. (Ibidem, p. 210)

\section{Considerações finais}

O nosso interesse em analisar questões gramaticais nos dicionários surgiu durante os estudos do Vocabulario da Lingoa de Iapam (1603), quando percebemos a apresentação dos verbetes dos verbos. Neles, à semelhança dos dicionários bilíngues de latim, o lema fornece três variações morfológicas. Como docente de língua japonesa como língua estrangeira, percebíamos dificuldade de apreensão de formas de verbos quando estes eram sucedidos pelos morfemas "ta" e "te". Uma das formas verbais que o dicionário dos jesuítas fornece é justamente a 
desinência verbal já unido ao morfema "ta". Como afirmamos antes, essa prática foi reproduzida nos dicionários de Hepburen, mas somente nas edições de 1868 e 1872. A mais nova, de 1868, aboliu esta forma.

Chamados de verbos-adjetivos pelo padre João Rodrigues (c.1561-1633), os adjetivos chamados keiyôshi na gramática normativa japonesa hoje, também foram registrados no Vocabulario da Lingoa de Iapam de modo que se podem conhecer pelo menos quatro formas: a atributiva/rentaikei e final/shûshikei, as quais são idênticas, e a adverbial/ren'yôkei e continuativa/chûshikei, que também são iguais. Apesar de a língua japonesa não possuir, nos seus verbos e adjetivos, variação de forma tão distintas como nas línguas flexivas como é o caso do português, ter tais informações nos dicionários é de grande utilidade aos consulentes que não conhecem as noções básicas da morfossintaxe do japonês, e também àqueles que o estudam.

O mesmo se pode dizer dos keiyôdôshi. Os dicionários dos Jesuítas e de Hepburn nos informam as formas atributiva/rentaikei e adverbial/ren'yôkei, seja no interior de verbete, seja em verbetes distintos.

Como comentamos nos itens anteriores, a manutenção da equivalência gramatical, sempre de possível, e os exemplos, embora poucos, permitiram que os autores deixassem de inserir explicações longas de seus usos.

Seguindo a tendência dos dicionários bilíngues modernos, Ôtake indexou, nos lemas de verbos e adjetivos, apenas as formas julgadas básicas. Limitando-nos aos adjetivos keiyôshi e keiyôdôshi, que analisamos, Ôtake manteve a equivalência gramatical das desinências dos adjetivos com as respectivas traduções, além de fornecer sinônimos em japonês nas formas equivalentes, considerando que elaborou o seu dicionário para os japoneses que emigravam para o Brasil.

Introduzir questões gramaticais nos dicionários requer a seleção, pelo dicionarista, de uma teoria. Embora seja uma questão básica, escolher entre incorporar “ada 徒” ou “ada-na 徒な” ou “adana 徒な” como lema é seguir distintas teorias gramaticais. Mesmo assim, voltar a produzir dicionários bilíngues cujos lemas contenham desinências das variações verbais e adjetivais, sendo, por isso, de fácil consulta, seria de grande utilidade aos aprendizes do idioma.

\section{Referências bibliográficas}

HEPBURN, James Curtis. Wa ei gorin shûsei / A Japanese and English dictionary: with an English and Japanese index. Shangai: American Presbyterian Mission Press, 1867. (Disponível em http://www.meijigakuin.ac.jp/mgda/waei/, consultado em 23/01/2015)

HEPBURN, James Curtis. Wa ei gorin shûsei / A Japanese-English and English-Japanese dictionary. Second edition. Shangai: American presbyterian mission press, 1872. (Reproduzida em 1970, em obra que contém notas de Takashi Kamei, editada pela Tôyô 
bunko, em Tóquio)

HEPBURN, James Curtis. Kaisei Zôho Wa ei, ei wa gorin shûsei / A Japanese-English and English-Japanese dictionary. Third edition. Tóquio: Z.P Maruya \& Co., Limited; Yokohama: Kely \& Wally, Limited; Nova Iorque: Steiger \& Co.; Londres: Trïbner \& Co, 1886. (Reproduzida em 1980, em obra organizada e explicada por Akira Matsumura e publicada pela editora Kôdansha, em Tóquio)

HORIE, Yoshifumi. Nippaku yûkô no ishizue - Ôtake Wasaburô, jisho henshû to sûkina shôgai (Pilares da amizade Brasil-Japão - Ôtake Wasaburô, compilação do dicionário e vida de vicissitudes). São Paulo: Centro de Estudos Nipo-Brasileiros, 2008.

JESUÍTAS ${ }^{14}$. Vocabulario da Lingoa de Japam. Nagasaki: Companhia de Jesus, 1603. (Reproduzida em 1998, em obra organizada por Mitsunobu Ôtsuka e publicada pela editora Seimondô de Osaka)

KINDAICHI, Haruhiko. Kokugo jiten no ayumi (A evolução dos dicionários do vernáculo [japonês]). In Jiten kyôkai. Nihon no jisho no ayumi (A evolução dos dicionários do Japão). Tóquio: Jiten kyôkai, 1996, pp.19-21.

KURASAHIMA, Tokihisa. Jisho to Nihongo - Kokugo jiten wo kaibô suru (O dicionário e a língua japonesa - Dissecando do dicionário japonês). Tóquio: Kôbunsha, 2002.

MATSUYAMA, Iwao. Gojûonzu jun hairetsu ni kansuru ichi kôsatsu - Aru chûgaku nyûshi wo daizai ni / The Hidden Rules in the Goju-on Collation Order of Japanese Character String. In Tamagawa Daigaku Kyôikugakubu Kiyô. Tóquio: 2011, pp. 65-96.

ÔTAKE, Wasaburô. Wa-po jiten / Diccionario Japonez-Portuguez. Reimpressão da primeira edição de 1925, por Shin'ichi Ôtake. Tóquio: Shin'ichi Ôtake, 1976.

RODRIGUES, João. Arte da Lingoa de Iapam composta pello Padre Ioão Rodriguez Portugues da Cõpanhia de IESV dividida em tres livros. Nangasaqui, 1608. (Edição fac-similar publicada pela editora Benseisha, de Tóquio, em 1977)

TASHIRO, Eliza Atsuko. A lexicografia japonesa nos períodos Meiji-Taishô e Wasaburô Ôtake. In UFRJ-Faculdade de Letras, Departamento de Letras Orientais e Eslavas, Setor de Letras Japonesas. Anais do XIX Encontro Nacional de Professores Universitários de língua, literatura e cultura japonesa. Rio de Janeiro: 2008a, pp. 265-276.

TASHIRO (Perez), Eliza Atsuko. Dicionários que atravessaram oceanos. In Centro de Estudos Japoneses, Departamento de Letras Orientais, Faculdade de Filosofia, Letras e Ciências Humanas, Universidade de São Paulo, Estudos Japoneses № 28, São Paulo: Oficina Editorial, 2008b, pp. 217-230.

TASHIRO (Perez), Eliza Atsuko. Dictionaries that crossed Oceans. In BAXTER, James C.; HOSOKAWA, Shûhei; OTA, Junko. International Symposium in Brazil - Cultural Exchange between Brazil and Japan. Quioto: International Research Center for Japanese

14 Autora deste artigo preferiu manter a autoria JESUÍTAS ao invés de Anônimo como o fazem mitos outros pesquisadores. 
Studies, 2009, pp. 187-208. (Versão inglesa de "Dicionários que atravessaram oceanos" (TASHIRO 2008b)

TASHIRO, Eliza Atsuko. Dicionário de Wasaburô Ôtake (1872-1944) - Verbetes e termos gramaticais. In XATARA, Claudia. Estudos em lexicologia e lexicografia contrastiva. Curitiba: Honoris Causa Editora, 2010, pp. 59-76.

TASHIRO, Eliza Atsuko. Dicionários de Wasaburô Ôtake e análise das classes gramaticais 'secundárias'. In Estudos Japoneses na América Latina, volume 1. São Paulo: Editora Lexia, 2015.

YAMADA, Toshio. Nihongo to jisho (A língua japonesa e o dicionário). Chûkô shinsho 494. Tóquio: Chûôkôronsha, 1978. 